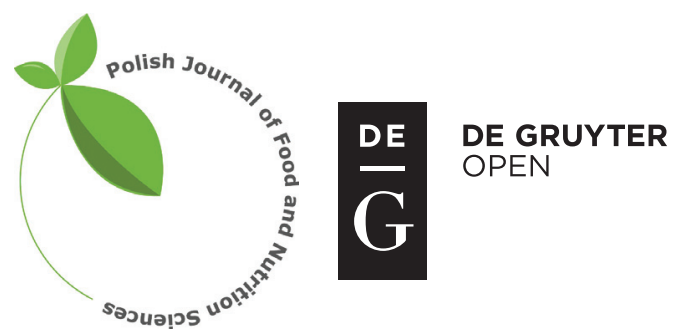

Pol. J. Food Nutr. Sci., 2018, Vol. 68, No. 3, pp. 195-205

DOI: $10.1515 /$ pjfns-2017-0025 http://journal.pan.olsztyn.pl

Original research article

Section: Food Chemistry

\title{
Microwave Irradiation Enhances the Germination Rate of Tartary Buckwheat and Content of Some Compounds in Its Sprouts
}

\author{
Shunmin Wang*, Jianfei Wang, Yubao Guo \\ Biological and Chemical Engineering Institute, Anhui Polytechnic University, Wuhu 241000, China
}

Key words: tartary buckwheat, microwave treatment, germination, sprouts

Tartary buckwheat (Fagopyrum tataricum) seeds were irradiated with microwaves at various power levels of 200, 400, 600 and $800 \mathrm{~W}$ for 10 or $30 \mathrm{~s}$. The irradiated grains were germinated for 3,5, and 7 days and harvested. The germination rate of the tartary buckwheat seeds and contents of some compounds in the sprouts were investigated. The results showed that the exposure to $600 \mathrm{~W}$ microwaves for $10 \mathrm{~s}$ resulted in the highest final germination rate after 7 days of germination, which was 2 times that of the control. The exposure of seeds to $800 \mathrm{~W}$ for $30 \mathrm{~s}$ showed the lowest germination rate (approximately 10\%), which decreased by $87 \%$ compared with the control $(p<0.05)$. The exposure at $600 \mathrm{~W}$ for $30 \mathrm{~s}$ stimulated the total flavones content, reduced the sugar and soluble protein contents, and increased the 2,2-diphenyl-1-picrylhydrazyl (DPPH) radical scavenging activity. The highest free amino acid content $(11 \mathrm{mg} / \mathrm{g})$ was observed in 5-day sprouts exposed to $800 \mathrm{~W}$ for $10 \mathrm{~s}$. Moreover, the microwave treatment had a positive effect on the catalase (CAT) and superoxide dismutase (SOD) activity.

\section{INTRODUCTION}

Seed germination is the most important period in the life cycle of a higher plant and involves a series of morphological, physiological and biochemical changes. The germinated grain has improved digestibility and bio-availability of nutrients; for example, after germination vitamin content increases [Rajjou et al., 2012], and the amino acid composition is regulated to change more reasonably. Moreover, the contents of $\gamma$-aminobutyric acid (GABA) [Guo et al., 2016], free amino acids, phenolics, and other active ingredients that have a unique nutritional value and health functions in the sprouted grain are significantly diversified [Doblado et al., 2007].

Tartary buckwheat (Fagopyrum tataricum) is a medicinal and edible plant that is extremely rich in bioactive ingredients such as flavonoids [Li et al., 2016; Fabjan et al., 2003] and GABA. The flavonoid rutin increases after germination so that the nutritional value and the biological activity are significantly improved [Zhang et al., 2015; Nam et al., 2015]. Most non-invasive techniques include treatment with electromagnetic waves, particularly microwaves, optical emissions, magnetic fields, ultrasound and blue light - UV radiation, which has been used in agriculture to improve seed germination and increase the yield of biologically-active components. Some previous studies have indicated that physical treatments, including magnetic fields [Zhou et al., 2015a], electric fields, supersonic [Onac et al., 2016; Yu et al., 2016], and high

\footnotetext{
* Corresponding Author: Tel./Fax: +86 553 2871254;

E-mail: wangshunmin@126.com (S. Wang)
}

pressure treatments [Doblado et al., 2007], induce effects in the plant tissue [Carbonell et al., 2000], thereby regulating the progress of germination [Kadlec et al., 2001; Aladjadjiyan, 2012]. These physical factors can stimulate phenylalanine ammonialyase (PAL) and chalconeisomerase (CHI) during the germination of buckwheat seeds to increase flavonoid synthesis [Roux et al., 2006; Pelletier et al., 1999]. The activities of the two key enzymes, PAL and CHI, have a close relationship with the total flavonoid content during the germination of buckwheat sprouts [Li et al., 2011]. The two enzymes act synergistically during the time course of both dark and light conditions to yield the maximum total flavonoid content in tartary buckwheat sprouts [Thwe et al., 2014; Ji et al., 2016]. The activity of PAL and CHI was also in accordance with the variety of total flavonoid content. Therefore, light [Ji et al., 2016] and magnetic field [Asghar et al., 2016] can influence flavonoid content by changing the activity of PAL and CHI. Microwaves are a form of electromagnetic radiation, with a frequency between 30 and $300 \mathrm{GHz}$, that has been shown to significantly stimulate germination [Gaurilcikiene et al., 2013]. As a type of electromagnetic wave, a microwave at a certain power can effectively activate various enzymes involved in seed germination [Radzevičius et al., 2013], significantly improving the germination rate (GR) and increasing the synthesis of certain biological components in the seeds [Stan et al., 2014]. Microwave pretreatment promotes the expression of the genes encoding peroxidase (POD) and superoxide dismutase (SOD) isozymes in plant seedlings [Aladjadjiyan, 2012] to significantly increase the germination potential, GR, stem length, root length and the total mass 
of the seeds [Radzevičius et al., 2013]. Moreover, this increase was positively correlated with the microwave power [Eupinska et al., 2009; Han, 2010]. The protein and amino acid contents of wheat seedlings increased when the seeds were pretreated with microwaves, and the increase was microwave irradiation dose-dependent [Hamada, 2007]. The dose- dependency may be related to the changes in the protein structure of the enzyme due to the microwave treatment [Damm et al., 2012].

A previous study showed that microwave pretreatment of broad beans increased the phenolic content and levodihydroxy phenylalanine (1 - DOPA) in seedlings by $700 \%$ and 59\%, respectively [Randhir \& Shetty, 2004]. Microwave pretreatment of rice and millet increased the tocopherol content of the germ oil of rice by $150 \%$ and the phytosterol content by $15 \%$, and it slightly increased the GABA content [Kwon et al., 2004]. Moreover, the acceptable biological polyphenol content of the millets increased significantly [Hithamani \& Srinivasan, 2014]. Wheat (Triticum aestivum L. Sakha 61) seeds irradiated with microwaves for a long time $(75 \mathrm{~min})$ showed a 7 -fold higher carotenoid content in the seedlings than in the control sample 7 days after germination. The protein and amino acid contents also increased, and the total sugar content decreased. However, treatment for a shorter time $(15 \mathrm{~min})$ stimulated proline synthesis in the seedlings [Hamada, 2007]. Microwave irradiation of brown rice significantly increased GABA, the total phenolic content and the DPPH RSA (radical scavenging activity, RSA) [Seo et al., 2016], indicating that microwaves can increase the secondary metabolite content and the nutritive value of sprouts and grains and thereby improve the quality of the germinated grain [Uppal \& Bains, 2012].

Pretreatment with microwaves activates the POD and SOD isozymes at some gene loci and enhances their expression in seedlings [Aladjadjiyan, 2012]; therefore, they can maintain the integrity of the cell membrane and the antioxidant capacity, which enhances plant stress resistance [Chen et al., 2009a]. Seeds irradiated with microwaves followed by salt stress restored plant growth parameters and biochemical parameters related to an oxidative status almost to the levels of non-salt-treated seedlings. The results indicated that irradiating wheat seeds with a suitable dose of microwave radiation could enhance the tolerance of seedlings to salt stress [Chen et al., 2009a; Chen et al., 2009b]. Microwaves improve the activities of some enzymes in Isatis indigotica cotyledons, including amylase, alanine aminotransferase and protease, and they accelerate cell metabolism and significantly increase biophoton emissions [Chen et al., 2005]. Ultrasound stress [Dhawi \& Al Khayri, 2011] induced the expression of the PAL and CHI genes. To adapt to the invasive stress conferred by microwaves, plants regulate the activity of certain enzymes and improve the content of osmolytes, flavonoids and proline.

The studies mentioned above showed that pretreatment with microwaves promotes seed germination and early metabolism; however, there are a few studies on seeds regarding short-term (effects on seed germination) or long-term effects (effects on seedling growth, metabolism and biomass accumulation) of the dosage and treatment times of microwaves, particularly in buckwheat seeds. Therefore, the pur- pose of this study was to investigate the effects of microwave irradiation on the germination characteristics of tartary buckwheat seeds and the physiological and biochemical indexes in the germinating seeds.

\section{MATERIAL AND METHODS}

\section{Materials and chemical reagents}

Ning Qiao NO.2 tartary buckwheat seeds (Fagopyrum esculentum) were obtained from the Yanchi seed company in NingXia province of China. Chemical reagents such as rutin (purity $>99 \%$ ) and the other reagents were purchased from the Sinopharm Chemical Reagent Co., Ltd. The microwave source was a Japanese Panasonic NN - K597WS microwave oven (modified for this study) with variable power from 200 to $900 \mathrm{~W}$ and a frequency of $2450 \mathrm{MHz}$.

\section{Germination procedures}

Tartary buckwheat seeds were sterilized with a $1.0 \mathrm{~g} / \mathrm{L}$ potassium permanganate solution for approximately $5 \mathrm{~min}$ at room temperature $\left(30^{\circ} \mathrm{C}\right)$ and washed three times with distilled water. Before germination, the seeds were soaked in distilled water at $30^{\circ} \mathrm{C}$ for $4 \mathrm{~h}$, and the water was changed once again during this period. The seeds were transferred to warm water $\left(55 \pm 1^{\circ} \mathrm{C}\right)$ for approximately $15 \mathrm{~min}$ to induce germination.

\section{Microwave pretreatment methods}

Tartary buckwheat seeds were artificially germinated; then, 50 grams of seeds were separated into three groups and placed in 9-cm diameter culture dishes. Each group contained approximately 50 ears (approximately 1.0 gram). The seeds were placed in a microwave oven for irradiation by microwaves. The tartary buckwheat grains were exposed to microwave irradiation at $200,400,600$ and $800 \mathrm{~W}$ for 10 or $30 \mathrm{~s}$, and they were covered with two pieces of filter paper. The experiment consisted of nine treatments of microwave irradiation: $0 \mathrm{~s}$ (CK, the control), $200 \mathrm{~W}$ for $10 \mathrm{~s}$ and $30 \mathrm{~s}, 400 \mathrm{~W}$ for $10 \mathrm{~s}$ and $30 \mathrm{~s}, 600 \mathrm{~W}$ for $10 \mathrm{~s}$ and $30 \mathrm{~s}$, and $800 \mathrm{~W}$ for $10 \mathrm{~s}$ and $30 \mathrm{~s}$. The seeds were incubated at $85 \% \mathrm{RH}$ and $25 \pm 2^{\circ} \mathrm{C}$ for 7 days in a seed germination incubator. The seeds were rinsed with $8 \mathrm{~mL}$ distilled water every $12 \mathrm{~h}$ during the incubation period. Seeds not treated with microwave were used as the control (CK). The sprouts were promptly removed after germination and stored at $-80^{\circ} \mathrm{C}$ until use.

\section{Germination rate}

From the beginning of incubation, the GR of the seeds was measured every $12 \mathrm{~h}$ (germination was defined as a sprout length of greater than $1 / 2$ the seed length). The average was calculated $(\mathrm{GR}=$ germinating seeds/total seeds $\times 100 \%)$, and the GR was evaluated for the subsequent 7 days. The final GR was the germination after 7 days.

\section{Total flavonoids}

Content of total flavonoids was determined by a sodium nitrite-aluminum nitrate colorimetric method based on the method of Ji et al. [2016] with some modifications. One gram of freeze-dried tartary buckwheat sprouts was placed into a mortar and immersed in $5 \mathrm{~mL} \mathrm{60 \%} \mathrm{(v/v)} \mathrm{ethanol;} \mathrm{some}$ 
quartz sand was added, and the mixture was evenly ground. An additional volume of $60 \%(\mathrm{v} / \mathrm{v})$ ethanol was added to bring the solution to $50 \mathrm{~mL}$, which was centrifuged at $9000 \times \mathrm{g}$ for $10 \mathrm{~min}$. The supernatant was the sample extract. Next, $1 \mathrm{~mL}$ of the sample extract was transferred to a $10-\mathrm{mL}$ volumetric flask, and $2 \mathrm{~mL}$ of $0.1 \mathrm{M}$ aluminum chloride solution and $3 \mathrm{~mL}$ of $1 \mathrm{M}$ potassium acetate were added. The mixture was diluted to $10 \mathrm{~mL}$ with $60 \%$ (v/v) ethanol, mixed well and maintained in the dark for $30 \mathrm{~min}$. The absorbance was measured at $420 \mathrm{~nm}$. Rutin was used to create a standard curve, and the total flavonoids were expressed as rutin equivalents [Ji et al., 2016].

$$
\mathrm{A}_{420}=4.0556(\mathrm{mg} / \mathrm{mL}) \text { rutin }+0.0003, \mathrm{R}^{2}=0.999
$$

\section{Contents of dry matter, total soluble sugar, reducing sugar, soluble protein, and free amino acids}

Contents of dry matter, total soluble sugar, reducing sugar, soluble protein and free amino acids in tartary buckwheat seeds during sprouting was determined according to the following methods. Dry matter content (\%) was determined after drying at $60^{\circ} \mathrm{C}$ to a constant weight, with a reproducibility rate of $0.02 \%$. The total soluble sugar and soluble protein contents were estimated as described by Wang et al. [2001]. The free amino acid content was determined according to the method of Aragão et al. [2015], whereas the content of reducing sugars was measured according to the standard AOAC methods 939.03 [AOAC, 1995].

\section{Catalase and superoxide dismutase activity}

The enzymes were extracted from 0.5 grams of seedlings using a mortar and pestle with $5 \mathrm{~mL}$ extraction buffer containing $50 \mathrm{mM}$ potassium phosphate buffer $(\mathrm{pH}$ 7.6) and $0.1 \mathrm{mM}$ disodium ethylenediamine tetraacetate $\left(\mathrm{Na}_{2}-\right.$ EDTA). The homogenate was centrifuged at $15,000 \times g$ for $15 \mathrm{~min}$, and the supernatant was assayed for the various enzymes. All steps in the preparation of the enzyme extracts were performed at $4^{\circ} \mathrm{C}$ in an ice bath. SOD was assayed according to Fikret et al. [2013] by monitoring the superoxide radical-induced reduction of nitro blue tetrazolium (NBT) at $560 \mathrm{~nm}$. One unit of SOD activity was defined as the amount of enzyme that caused a $50 \%$ inhibition in the photochemical reduction of NBT. The catalase (CAT) activity was determined by monitoring the disappearance of $\mathrm{H}_{2} \mathrm{O}_{2}$ according to the method of Fikret et al. [2013].

\section{DPPH radical scavenging activity}

The DPPH radical scavenging activity (RSA) was measured according to the method described by Zhou et al. [2015b] and Ji et al. [2016] with some modifications. Briefly, $0.2 \mathrm{~mL}$ of a previously prepared $60 \%$ (v/v) ethanol extract was added to $7.8 \mathrm{~mL}, 0.025 \mathrm{mg} / \mathrm{mL}$ DPPH in ethanol. The mixture was incubated at room temperature in the dark for $30 \mathrm{~min}$, and the absorbance was measured at $517 \mathrm{~nm}\left(\mathrm{~A}_{\mathrm{T}}\right)$. A pure DPPH solution was used as the control, and its absorbance at $517 \mathrm{~nm}$ was set as $\mathrm{A}_{0}$. The DPPH RSA was calculated as follows [Ji et al., 2016]:

$$
\operatorname{RSA}(\%)=\left(\mathrm{A}_{0}-\mathrm{A}_{\mathrm{T}}\right) \times 100 / \mathrm{A}_{0}
$$

\section{Statistical analysis}

Quantitative analyses were performed in triplicate on sprouts treated and untreated with microwaves. The data were expressed as the mean and standard deviation and analyzed with one-way ANOVA followed by Duncan's multiple range test. The significance level was $P<0.05$. The software program SPSS (SPSS Inc., Chicago, IL, USA) was used for the analyses.

\section{RESULTS}

\section{Effect of microwaves on the germination rate}

Figure 1 shows the GR of tartary buckwheat seeds after irradiation at different power levels for different times. Microwaves (200 to $800 \mathrm{~W}$ ) applied for $10 \mathrm{~s}$ or $30 \mathrm{~s}$ significantly $(P<0.05)$ affected the germination of tartary buckwheat seeds. The GR after 2 days was $47 \%$ when the seeds were exposed to $600 \mathrm{~W}$ microwaves for $10 \mathrm{~s}$, which showed a $54 \%$
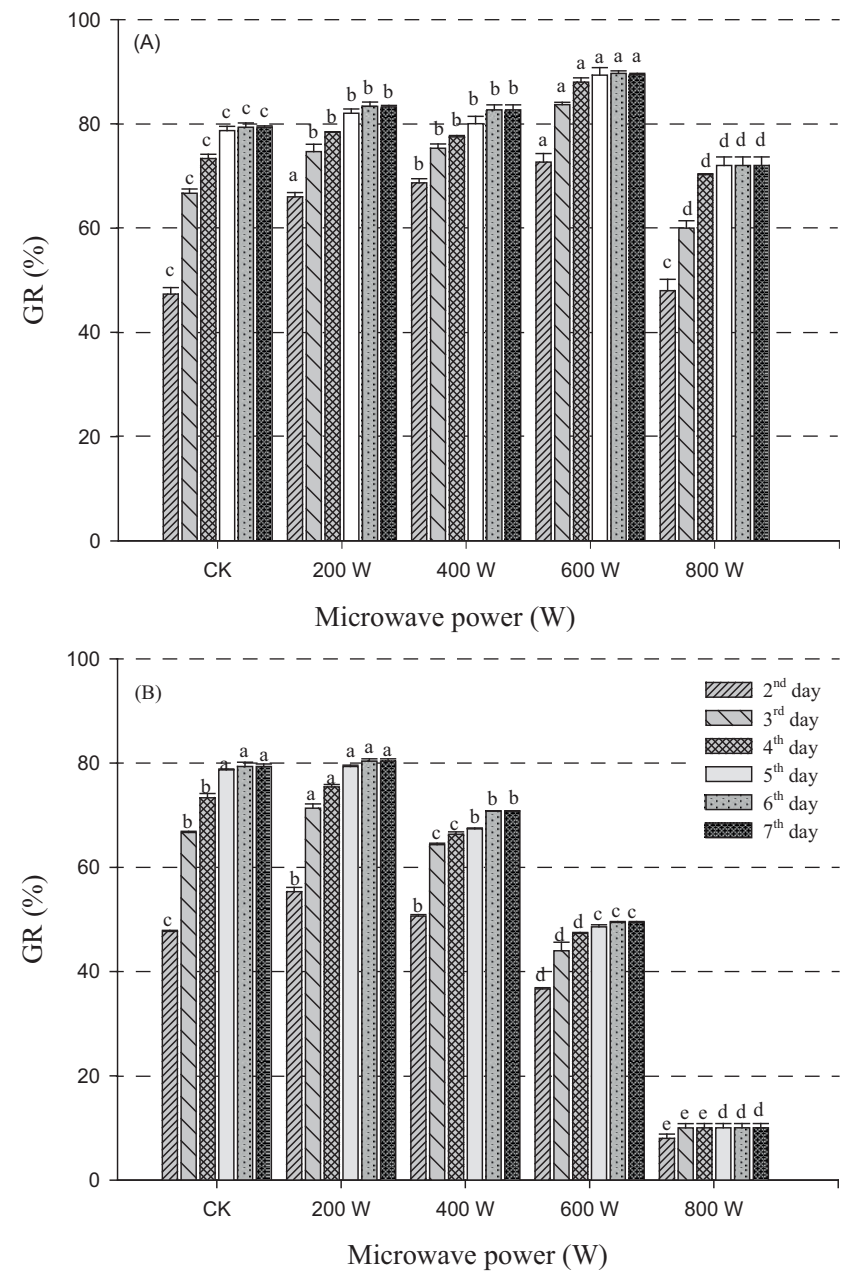

FIGURE 1. Changes in the germination rate of tartary buckwheat sprouts in response to different microwave treatments.

(A) Treatment time $10 \mathrm{~s}$; (B) Treatment time $30 \mathrm{~s}$. All values are the means $\pm S D(n=50)$. Values of the GR among microwave treatments with different power levels shown with different lowercase letters are significantly different by ANOVA with Duncan's multiple range test at $P<0.05$. CK is the control. Seeds that were treated with microwaves at $800 \mathrm{~W}$ for $30 \mathrm{~s}$ had the lowest GR. The data of the test for the contents and enzyme activity is not shown. 

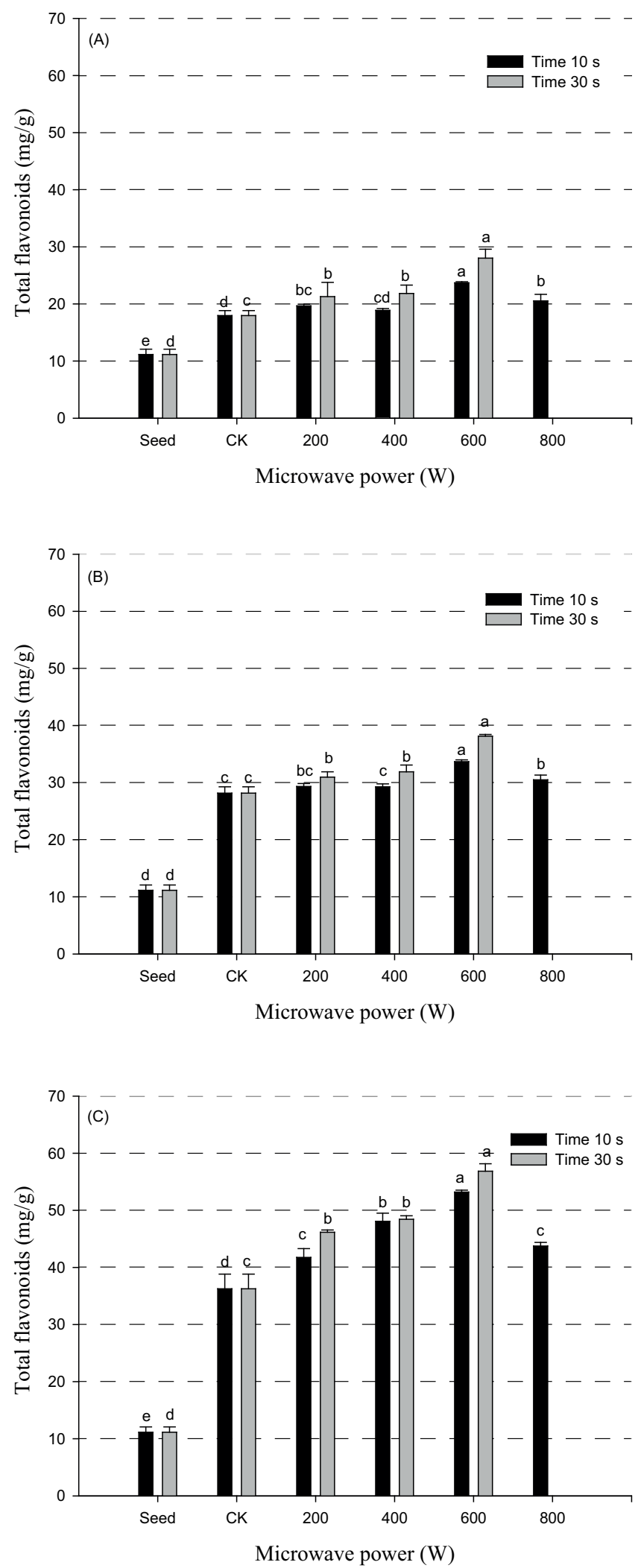

FIGURE 2. Changes in the total flavonoid content of tartary buckwheat sprouts in response to different microwave treatments.

(A) 3-day sprout; (B) 5-day sprout; (C) 7-day sprout. All values are the means $\pm \mathrm{SD}(\mathrm{n}=50)$. Values of the total flavonoid content with different microwave power levels shown with different lowercase letters are significantly different by ANOVA with Duncan's multiple range test at $P<0.05$. $\mathrm{CK}$ is the control. Seeds that were treated with microwaves at $800 \mathrm{~W}$ for $30 \mathrm{~s}$ had the lowest GR. The data of the test for the total flavonoid content is not shown. increase compared with the control. The GR at $800 \mathrm{~W}$ microwave exposure for $10 \mathrm{~s}$ was $48 \%$, but no significant difference $(P>0.05)$ was observed compared with the control. After incubation for 7 days, the GR of seeds exposed to $600 \mathrm{~W}$ for $10 \mathrm{~s}$ was the highest (89\%), which increased $13 \%$ compared with the control. The GR of seeds exposed to $800 \mathrm{~W}$ for $10 \mathrm{~s}$ was the lowest (72\%), which was a significant decrease $(10 \%)$ compared with the control $(P<0.05)$.

The results in Figure 1 show that the GR decreased with an increase in the microwave power from $200 \mathrm{~W}$ to $800 \mathrm{~W}$ for $30 \mathrm{~s}$ when the seeds were incubated for 2 days. When the microwave power was $200 \mathrm{~W}$ for $30 \mathrm{~s}$, the GR was $55 \%$, showing an increase of $17 \%(P<0.05)$ compared with the control. At $800 \mathrm{~W}$ for $30 \mathrm{~s}$, the GR was only $8 \%$, which indicates a significant reduction of $83 \%$ compared with the control $(P<0.05)$. The highest GR $(80 \%)$ was observed after 7 days at $200 \mathrm{~W}$ for $30 \mathrm{~s}$.

\section{Effect of microwaves on total flavonoids}

As shown in Figure 2, three days after the microwave treatment at $600 \mathrm{~W}$ for $10 \mathrm{~s}$, the total flavonoid content of the sprouts was $24 \mathrm{mg} / \mathrm{g}$, which showed $113 \%$ and $32 \%$ increases compared with seeds and the control, respectively $(P<0.05)$. The total flavonoid content after the microwave treatment of $600 \mathrm{~W}$ for $30 \mathrm{~s}$ was $28 \mathrm{mg} / \mathrm{g}$, which showed an increase of $151 \%$ and $56 \%$ compared with the seeds and the control, respectively. The total flavonoid content of sprouts after the microwave treatment of $30 \mathrm{~s}$ was slightly higher than after $10 \mathrm{~s}$ and the same microwave power (Figure $2 \mathrm{~A}$ ). After 5 days (Figure $2 \mathrm{~B}$ ), the total flavonoid content of sprouts treated with $600 \mathrm{~W}$ for $10 \mathrm{~s}$ was $34 \mathrm{mg} / \mathrm{g}$, showing an increase of $202 \%$ and $20 \%$ compared with seeds and the control, respectively. At $600 \mathrm{~W}$ for $30 \mathrm{~s}$, the total flavonoid content was $38 \mathrm{mg} / \mathrm{g}$, indicating an increase of $242 \%$ and $35 \%$ compared with the seeds and control $(P<0.05)$. Finally, a treatment of $600 \mathrm{~W}$ for $10 \mathrm{~s}$ produced $53 \mathrm{mg} / \mathrm{g}$ of total flavonoids in the sprouts after 7 days, which indicated an increase of $377 \%$ and $89 \%$ compared with that in seeds and the control (Figure $2 \mathrm{C}$ ). However, at $600 \mathrm{~W}$ for $30 \mathrm{~s}$, the sprouts showed the highest total flavonoid content of $57 \mathrm{mg} / \mathrm{g}(P<0.05)$.

\section{Effect of microwave treatment on contents of total soluble sugars and reducing sugars}

As shown in Table 1, the total soluble sugar content of sprouts decreased with an increase in microwave power $(P<0.05)$. After 7 days, sprouts treated with microwave at $800 \mathrm{~W}$ for $10 \mathrm{~s}$ had a total soluble sugar content of $134 \mathrm{mg} / \mathrm{g}$. Compared with seeds and the control, the total soluble sugar content decreased by approximately $23 \%$ and $9 \%$, respectively. For the microwave treatment of $600 \mathrm{~W}$ for $30 \mathrm{~s}$, the total soluble sugar content was $132 \mathrm{mg} / \mathrm{g}$, showing a decrease of $24 \%$ and $11 \%$ compared with seeds and the control. However, for a power of $600 \mathrm{~W}$ for $30 \mathrm{~s}$, the total soluble sugar content in the sprouts decreased to $132 \mathrm{mg} / \mathrm{g}(P<0.05)$.

Microwave treatment resulted in significant differences $(P<0.05)$ in the content of reducing sugars in sprouts (Table 1). An increase in the microwave power from 200 to $800 \mathrm{~W}$ first increased then decreased the reducing sugar content of the sprouts. For a microwave treatment of $600 \mathrm{~W}$ ap- 

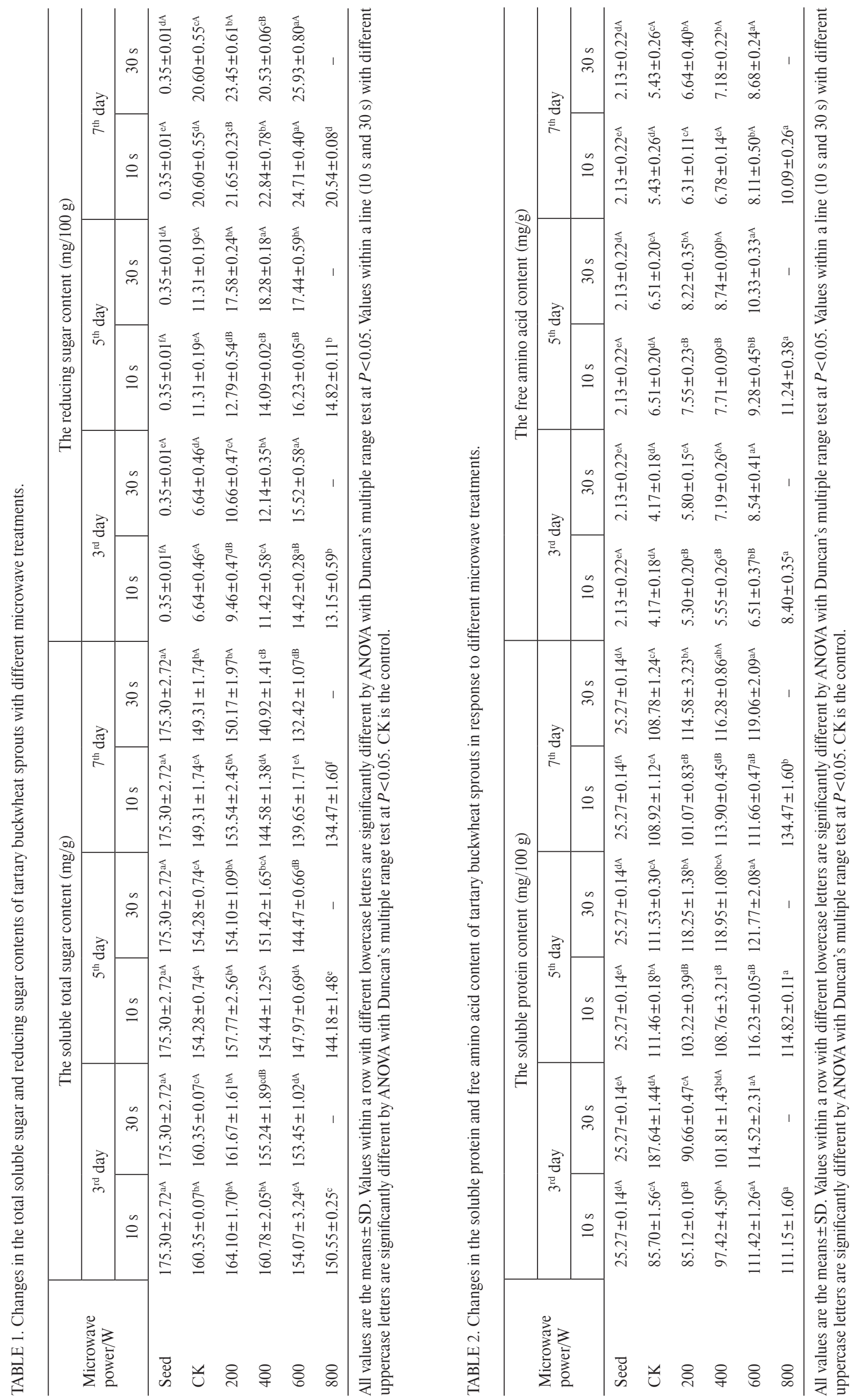
plied for $10 \mathrm{~s}$, the reducing sugar content of 3-day sprouts was $14.42 \mathrm{mg} / 100 \mathrm{mg}$, showing a 40 -fold and $117 \%$ increase compared with that of seeds and the control, respectively. For a microwave treatment of $600 \mathrm{~W}$ for $30 \mathrm{~s}$ after 5 days, the reducing sugar content was $18 \mathrm{mg} / 100 \mathrm{mg}$, showing an increase of approximately $13 \%$ compared to exposure to $600 \mathrm{~W}$ for $10 \mathrm{~s}$ (Table 1). After 7 days (Table 1), a microwave treatment at $600 \mathrm{~W}$ for $30 \mathrm{~s}$ produced the highest reducing sugar content of $26 \mathrm{mg} / 100 \mathrm{mg}$ in the sprouts, which increased 72-fold and $26 \%$ compared with that in seeds and the control, respectively $(P<0.05)$.

\section{Effect of microwave treatment on contents of soluble protein and free amino acids}

As shown in Table 2, the soluble protein content in the sprouts first increased; then it decreased when the microwave power was increased from 200 to $800 \mathrm{~W}$. The soluble protein content of 3-day sprouts irradiated with $600 \mathrm{~W}$ for $10 \mathrm{~s}$ was $111 \mathrm{mg} / 100 \mathrm{mg}$, which showed $341 \%$ and $27 \%$ increases compared with that of seeds and control $(P<0.05)$. The $600 \mathrm{~W}$ for $30 \mathrm{~s}$ treatment increased soluble protein content approximately $3 \%$ more than that of $600 \mathrm{~W}$ for $10 \mathrm{~s}$ in the sprouts that were cultured for 5 days. The soluble protein content of sprouts irradiated with $600 \mathrm{~W}$ for $30 \mathrm{~s}$ increased approximately $9 \% \mathrm{com}$ pared with that of $600 \mathrm{~W}$ for $10 \mathrm{~s}$ and reached $122 \mathrm{mg} / 100 \mathrm{mg}$. However, the soluble protein content of 7-day tartary buckwheat sprouts reached $119 \mathrm{mg} / 100 \mathrm{mg}$ at $600 \mathrm{~W}$ for $30 \mathrm{~s}$. However, it increased by only approximately $370 \%$ and $9 \%$ compared with that of seeds and the control $(P<0.05)$.

The free amino acid content is shown in Table 2. It increased in sprouts with an increase in microwave power from 200 to $800 \mathrm{~W}$. For a microwave treatment of $800 \mathrm{~W}$ for $10 \mathrm{~s}$, the 5-day sprouts had the highest free amino acid content (11 mg/g), showing an increase of quadruple and 72\% compared with that of seeds and the control. At microwave powers of 200, 400 or $600 \mathrm{~W}$, the free amino acid content of sprouts treated for $30 \mathrm{~s}$ compared with $10 \mathrm{~s}$ increased by $9 \%, 13 \%$ and $11 \%$, respectively. After 7 days, the free amino acid content of the sprouts was less than that after 5 days $(P<0.05)$.

\section{Effect of microwave treatment on the catalase and superoxide dismutase activity}

As shown in Figure 3 (A, B and C), the effect of different microwave treatments on the CAT activity was significant $(P<0.5)$. When seeds were treated with microwaves at $600 \mathrm{~W}$ for $30 \mathrm{~s}$, the CAT activity in the seedlings peaked at $18.00,27.53$ and $30.70 \mathrm{mg} \mathrm{H}_{2} \mathrm{O}_{2} / \mathrm{g} \mathrm{FW} \times$ min after 3, 5 and 7 days, respectively. The CAT activity of the seedlings showed 4-, 4- and 3-fold increases compared to the control, respectively. The CAT activity increased with an increase in microwave power. At the same power, the CAT activity increased significantly when the treatment time was changed from $10 \mathrm{~s}$ to $30 \mathrm{~s}(P<0.5)$.

Microwave treatment had a significant effect on SOD activity $(P<0.5)$, as shown in Figure $3(\mathrm{D}, \mathrm{E}$ and $\mathrm{F})$. After germination for 3,5 and 7 days at $600 \mathrm{~W}$ for $30 \mathrm{~s}$, the SOD activity peaked approximately at 18, 22 and $23 \mathrm{U} / \mathrm{g}$, respectively. It increased by 58\%, 34\% and 39\%, respectively, compared with that of the control. The SOD activity increased with an increase in microwave power. At the same power, the SOD activity significantly increased when the treatment was extended from $10 \mathrm{~s}$ to $30 \mathrm{~s}(P<0.5)$. The SOD activity significantly increased from the $3^{\text {rd }}$ to the $5^{\text {th }}$ day, and this increase was reduced after 5 days.

\section{Effect of microwave treatment on DPPH radical scavenging activity}

As shown in Figure 4, when the microwave power was increased from 200 to $800 \mathrm{~W}$, the DPPH RSA also increased. For 7-day sprouts, the DPPH RSA for the $800 \mathrm{~W}$ for $10 \mathrm{~s}$ exposure was $62 \%$, showing an increase of $264 \%$ compared with seeds, while an exposure of $600 \mathrm{~W}$ for $30 \mathrm{~s}$ produced an activity of $67 \%$. Compared with a 10 -s treatment time, the DPPH RSA after $30 \mathrm{~s}$ increased by $4 \%, 5 \%$ and $7 \%$ at 200 , 400 , and $600 \mathrm{~W}$, respectively $(P<0.05)$.

\section{DISCUSSION}

Plant growth and development is modulated by internal cues and external environmental factors because plants are particularly sensitive to external environmental factors. The effects of microwave irradiation are based on the effects of temperature and electromagnetism on organisms. Previous studies have illustrated that certain doses of microwave irradiation notably improve the activities of nitric oxide synthase (NOS), CAT, POD, and SOD and increase the concentration of nitric oxide (NO), ascorbic acid (VC) and glutathione (GSH) [Chen et al., 2009a]. Radzevicius et al. [2013] reported that radish and carrot seeds exposed to $9 \mathrm{GHz}$ microwaves (80 kW) had 26\% and 11\% higher GR, respectively. According to our results (Figure 1), the lowest GR of $10 \%$ was observed at $800 \mathrm{~W}$ for $30 \mathrm{~s}$, which was $87 \%$ lower compared with the control $(P<0.05)$. The GR of tartary buckwheat seeds significantly increased $(P<0.05)$ as the microwave power increased but was significantly reduced when the exposure time was increased from $10 \mathrm{~s}$ to $30 \mathrm{~s}$ at higher irradiation power (>600 W) (Figure 1). These results were in accordance with previous studies in wheat [Ragha et al., 2011; Gaurilcikiene et al., 2013]. When the exposure time was extended, there was an improvement in the activities of the enzymes in the seedlings. In our study, the activity of CAT and SOD increased with increases in the microwave power and treatment time. Chen et al. [2009a] reported that $\alpha$-amylase activity in the seedlings first increased then decreased as the seed surface temperature increased when the wheat seeds were exposed to microwave radiation for $5,10,15,20$ and $25 \mathrm{~s}$, and the higher temperature harmed seed germination. The GR of lentil (Lens culinaris) seeds exposed to the microwave power of 450-730 W for 30 s was improved; however, this rate was inhibited for longer exposure times (60 and $90 \mathrm{~s}$ ) [Aladjadjiyan, 2010]. A lower power microwave pretreatment increased both POD and SOD activities and increased the GR and growth vigor [Chen et al., 2009a], but a higher power and longer duration caused more negative effects on wheat seeds. Thus, a low power microwave treatment for a short time improved the GR, but a low power for a longer time slightly affected the GR; however, the GR was inhibited when the seeds were incubated for longer times at high power levels. 

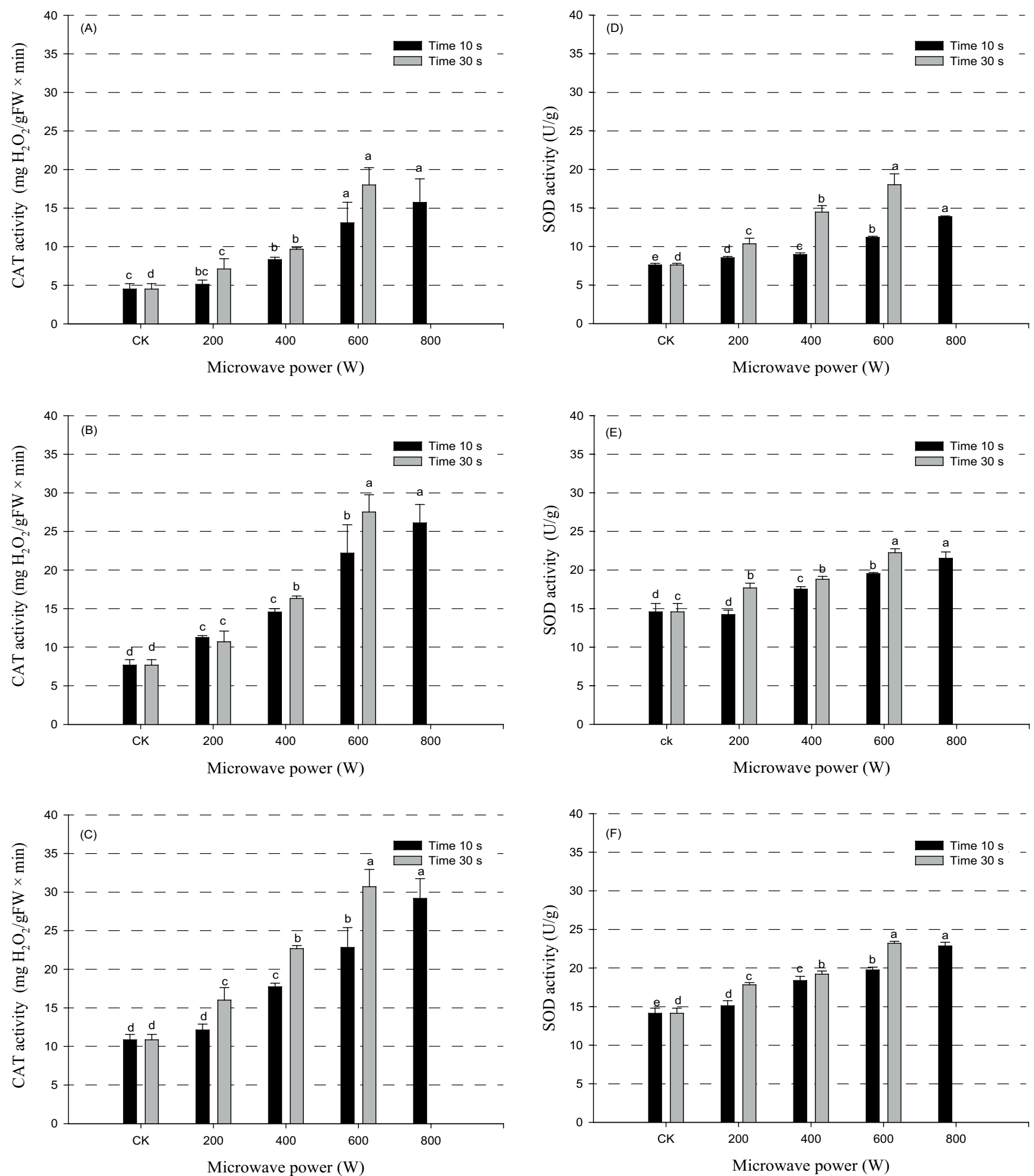

FIGURE 3. Changes in the catalase and superoxide dismutase activity of tartary buckwheat sprouts with different microwave treatments.

(A), (D): 3-day sprout; (B), (E): 5-day sprout; (C), (F): 7-day sprout. All values are the means \pm SD ( $\mathrm{n}=50$ ). Values of the catalase and superoxide dismutase activity with different microwave power levels shown with different lowercase letters are significantly different by ANOVA with Duncan's multiple range test at $P<0.05$. CK is the control. Seeds that were treated with microwaves at $800 \mathrm{~W}$ for $30 \mathrm{~s}$ had the lowest GR. The data of the test for the CAT and SOD activity is not shown.

Some non-invasive techniques such as blue light-UV [Ji et al., 2016] and microwaves are being used to increase the yield of biologically-active components. These non-thermal effects on seeds and biological objects are due to the direct interaction of the microwaves with molecules or tissue components since particles seek to orient themselves within an electric field and minimize the potential energy [Radzevičius et al., 2013]. Ji et al. [2016] reported that the total flavonoid content in the tartary buckwheat sprouts irradiated with blue light followed by UV-C (BL+UV-C) increased by 10\% compared with 

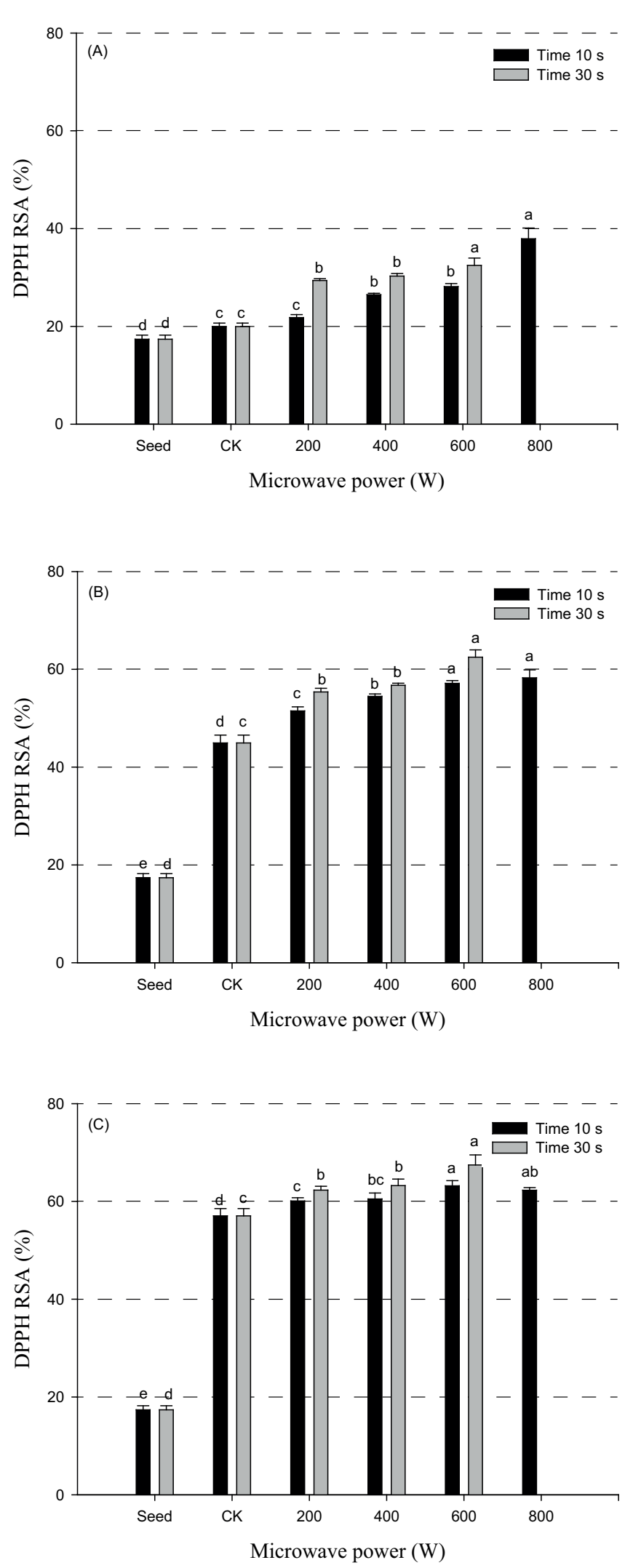

FIGURE 4. Changes in the DPPH radical scavenging activity of tartary buckwheat sprouts with different microwave treatments.

(A) 3-day sprout; (B) 5-day sprout; (C) 7-day sprout. All values are the means \pm SD $(n=50)$. Values of the DPPH RSA with different microwave power levels shown with different lowercase letters are significantly different by ANOVA with Duncan's multiple range test at $P<0.05$. CK is the control. Seeds that were treated with microwaves at $800 \mathrm{~W}$ for $30 \mathrm{~s}$ had the lowest GR. The data of the test for the DPPH RSA is not shown. the reverse sequence $(\mathrm{UV}-\mathrm{C}+\mathrm{BL})$. Various light-emitting diodes (LEDs) had an influence on the accumulation of phenolic compounds in tartary buckwheat sprouts [Seo et al., 2015]. The results indicated that microwave pretreatment increased some enzyme activities, GR and growth vigor [Chen et al., 2009a]. However, key enzymes (PAL, CHI and rutin degrading enzymes) were revealed to have a significant correlation with total flavonoids in tartary buckwheat sprouts [Ji et al., 2016]. Orsak et al. [2001] reported that microwave irradiation did not affect total polyphenols, but an increase in rutin increase was observed in some buckwheat samples. An increase of $78 \%$ was observed in the ascorbic acid content of the dry matter of potato tubers after microwave irradiation $(\mathrm{P}=90 \mathrm{~W}$, 0 - control, 200 and 400 s) [Orsak et al., 2001]. Zhou et al. [2015b] revealed that the total flavonoid content increased with an increase in the germination time of seeds. In our study, at the same treatment time, the total flavonoid content of sprouts first increased then decreased as microwave power increased. Under gentle microwave power, the total flavonoid content of sprouts increased as the exposure time increased.

In our study, at the same microwave power, the reducing sugar content of sprouts was higher at $30 \mathrm{~s}$ than $10 \mathrm{~s}$. Moreover, an increase in the microwave power increased the reducing sugar content of the sprouts when the seeds were exposed to microwaves for the same time. Germination can increase the soluble protein content of sprouts, which first increased and then decreased from 3-7 days after exposure. To some degree, a longer exposure time and higher microwave power increased the soluble protein content in tartary buckwheat sprouts. In a previous study, a decrease in the total protein and the total sugar content in germinated seeds was accompanied by an increase in amino acids and reducing sugars, respectively [Zhou et al., 2015b]. Microwave irradiation ( $\mathrm{P}=90 \mathrm{~W}, 0$ - control, 200 and $400 \mathrm{~s}$ ) caused a decrease in contents of all acids investigated including the phenolic amino acid L-tyrosine (L-Tyr), chlorogenic acid (CGA), caffeic acid (CA), and ferulic acid (FA) in three buckwheat samples (seeds, seedlings and plants: Fesculentum Moench, cv. Pyra and Emka and Tartarian buckwheat F. tataricum Gärtner) [Orsak et al., 2001]. Zhou et al. [2015b] demonstrated that the fatty acid contents showed no regular change trend with germination time for tartary buckwheat sprouts. Wheat (Triticum aestivum $L$.) grains were exposed to microwave radiation of wavelength $2.85 \mathrm{~cm}$ and a frequency of $10.525 \mathrm{GHz}$ for 15,45 , or $75 \mathrm{~min}$. The exposed grains were germinated and harvested after 7 and 14 days. The results showed that the microwave radiation increased the protein and amino acid content in wheat seedlings [Hamada, 2007]. Our study results concurred with those of Hamada et al. [2007]. At the same microwave power, the free amino acid content was reduced when the treatment time was extended from $10 \mathrm{~s}$ to $30 \mathrm{~s}$. The free amino acid content of sprouts increased with an increase of microwave power, and first increased and then decreased in 5-day seedlings.

The antioxidant activity in seeds and sprouts is associated not only with the content of active ingredients but also with the types of active ingredients, including $\mathrm{VC}$, vitamin E (VE), flavonoids, and carotenoids [Pasko et al., 2009]. Tartary buckwheat is rich in flavonoids [Li et al., 2016; Nam 
et al., 2015]. Lee et al. [2016] indicated that the antioxidant activity is associated with the flavonoid content, and different flavonoids contribute differently to the total antioxidant activity of common and tartary buckwheat. In our study, the effect of microwaves on the DPPH RSA of sprouts had a similar trend on the total flavonoid content. Some previous studies indicated that rutin had the highest RSA of various phenolic compounds and exhibited the strong DPPH RSA. Therefore, the DPPH RSA was greatly affected by rutin content [Ji et al., 2016]. A biochemical radical scavenging assay and gene expression results showed that the phenolic compounds in tartary buckwheat sprouts increased with a concomitant increase in the DPPH RSA upon exposure to L-phenylalanine (L-Phe) and LED lights [Seo et al., 2015], and cold stress [Li et al., 2015]. In our study, at the same microwave power, the DPPH RSA after a 30-s exposure was higher than after a 10-s exposure. At the same exposure time, an increase in the microwave power significantly increased the DPPH RSA. The DPPH RSA in sprouts increased when the seeds were germinated and as the germination time increased. Zhou et al. [2015a] reported a good accumulation in the total flavonoid content (approximately $20 \mathrm{mg}$ rutin/g), and rutin $(11 \mathrm{mg} / \mathrm{g})$ was found after 7 days of germination, and germination improved the activities of buckwheat extract to scavenge DPPH by $107 \%$. Furthermore, a correlation and principal component analysis showed that the total flavonoids and rutin content were closely and positively related to the free radical scavenging activity.

Thus, an increase in the microwave power significantly increased $(P<0.05)$ the GR of tartary buckwheat seeds. The GR of tartary buckwheat seeds were significantly reduced when the treatment time was increased from $10 \mathrm{~s}$ to $30 \mathrm{~s}$ at a higher microwave power. At a power $800 \mathrm{~W}$, the GR of the seeds was at a minimum and uniform germination was observed. However, gentle power $(200$ to $600 \mathrm{~W})$ for a short time $(10 \mathrm{~s})$, increased the content of total flavonoids, reducing sugars, soluble proteins and free amino acids as well as the DPPH RSA of sprouts with an increase in microwave power. However, the above mentioned parameters decreased when the power exceeded $600 \mathrm{~W}$. At the same power, the increase in exposure time from $10 \mathrm{~s}$ to $30 \mathrm{~s}$ increased the total flavonoid content, reducing sugar content and the DPPH RSA of the sprouts. However, as the microwave power was increased from 600 to $800 \mathrm{~W}$, the total soluble sugar content had an opposite trend. With a gentle microwave power treatment, extending the treatment time helped increase the total flavonoids and reducing sugar content of the sprouts after the seeds were germinated. Microwave pretreatment not only had a short-term effect on seed germination but also a long-term effect on seed germination capability, seedling development, metabolism and biomass compared with the control. The effects of microwave field patterns, power and time on other key enzyme activities and the composition of tartary buckwheat were not investigated in the present study but will be the subject of a follow-up study.

Moreover, due to variations in the material mass and moisture content and properties, hot spots can form in the different microwave cavity, which can lead to uneven energy absorption and heating during microwave irradiation. Therefore, the effect of variations in mass and moisture con- tent of wet material on the results should be considered with microwave irradiation. Unfortunately, the above problem has not been involved in this study.

\section{CONCLUSIONS}

Microwave treatment can increase the GR of the tartary buckwheat seeds. In summary, low-power and short exposure to microwaves can increase the GR of seeds; however, low power for a long time also affected seed germination, while exposure to a high power for a long time inhibited seed germination. When the seeds were treated with an appropriate dose of microwave irradiation and time, the microwave treatment increased the total flavonoid content, the soluble protein content, the reducing sugar content, the free amino acid content, and the activities of CAT and SOD in sprouts, thus improving the DPPH RSA.

\section{STUDY FUNDING}

This work was supported by the Natural Science Foundation of Higher Education Institutions of Anhui Province (KJ2016A061) and the National Natural Sciences Foundation Advance Research Program of Anhui Polytechnic University (2016yyzr08).

\section{CONFLICT OF INTERESTS}

Authors declare no conflict of interest.

\section{REFERENCES}

1. Aladjadjiyan A., Effect of microwave irradiation on seeds of lentils (Lens culinaris, Med.). Rom. J. Biophys., 2010, 20, 3, 213-221.

2. Aladjadjiyan A., Physical factors for plant growth stimulation improve food quality. 2012, 145-168. In Tech, Plovdiv, Bulgaria.

3. AOAC, Official Methods of Analysis (16th edn.). Methods 939.03. Arlington, VA: Association of Official Analytical Chemists International, 1995.

4. Aragão V.P.M., Navarro B.V., Passamani L.Z., Macedo A.F., Floh E.I.S., Silveira V., Santa-Catarina C., Free amino acids, polyamines, soluble sugars and proteins during seed germination and early seedling growth of Cedrela fissilis Vellozo (Meliaceae), an endangered hardwood species from the Atlantic Forest in Brazil. Theor. Exp. Plant. Phys., 2015, 27, 157-169.

5. Asghar T., Jamil Y., Iqbal M., Zia ul H., Abbas M., Laser light and magnetic field stimulation effect on biochemical, enzymes activities and chlorophyll contents in soybean seeds and seedlings during early growth stages. J. Photochem. Photobiol. B., 2016, 165, 283-290.

6. Carbonell M.V., Martinez E., Amaya J.M., Stimulation of germination in rice (Oryza satival.) by astatic magnetic field. Electro. Magnetobiol. Med., 2000, 19, 121-128.

7. Chen Y.P., Jia J.F., Han X.L., Weak microwave can alleviate water deficit induced by osmotic stress in wheat seedlings. Planta, 2009a, 229, 291-298.

8. Chen Y.P., Jia J.F., Wang Y.J., Weak microwave can enhance tolerance of wheat seedlings to salt stress. J. Plant. Growth. Reg., 2009b, 28, 381-385. 
9. Chen Y.P., Liu Y.J., Wang X.L., Ren Z.Y., Yue M., Effect of microwave and He-Ne laser on enzyme activity and biophoton emission of Isatis indigotica fort. J. Integr. Plant. Biol., 2005, 47, 849-855.

10. Damm M., Nusshold C., Cantillo D., Rechberger G.N., Gruber K., Sattler W., Kappe C.O., Can electromagnetic fields influence the structure and enzymatic digest of proteins? A critical evaluation of microwave-assisted proteomics protocols. J. Protemics, 2012, 75, 5533-5543.

11. Dhawi F., Al Khayri J.M., Magnetic field induced biochemical and growth changes in date palm seedlings. Date Palm Biotechnol., 2011, 287-309.

12. Doblado R., Frias J., Vidal-Valverde C., Changes in vitamin C content and antioxidant capacity of raw and germinated cowpea (Vigna sinensis var. carilla) seeds induced by high pressure treatment. Food. Chem., 2007, 101, 918-923

13. Fabjan N., Rode J., Kosir I.J., Wang Z., Zhang Z., Kreft I., Tartary buckwheat (Fagopyrum tataricum Gaertn.) as a source of dietary rutin and quercitrin. J. Agr. Food Chem., 2003, 51, 6452-6455.

14. Fikret Y., Manar T., Sebnem E., Sebnem K., Ozlem U., SOD, CAT, GR and APX enzyme activities in callus tissues of susceptible and tolerant eggplant varieties under salt stress. Res. J. Biotechnol., 2013, 8, 45-50.

15. Gaurilcikiene I., Ramanauskiene J., Dagys M., Simniskis R., Dabkevicius Z., Suproniene S., The effect of strong microwave electric field radiation on: (2) wheat (Triticum aestivum L.) seed germination and sanitation. Zemdirbyste, 2013, 100, 185-190.

16. Guo Y.X., Zhu Y.H., Chen C.X., Chen X.M., Effects of aeration treatment on gamma-aminobutyric acid accumulation in germinated tartary buckwheat (Fagopyrum tataricum). J. Chem., 2016, 2016, 1-9, art no. 4576758.

17. Hamada E.A.M., Effects of microwave treatment on growth, photosynthetic pigments and some metabolites of wheat. Biol. Plantarum, 2007, 51, 343-345.

18. Han F., The effect of microwave treatment on germination, vigour and health of China aster (Callistephus chinensis Nees.) seeds. J. Agr. Sci., 2010, 2, 4, 201-210.

19. Hithamani G., Srinivasan K., Bioaccessibility of polyphenols from wheat (Triticum aestivum), sorghum (Sorghum bicolor), green gram (Vigna radiata), and chickpea (Cicer arietinum) as influenced by domestic food processing. J. Agr. Food Chem., 2014, 62, 11170-11179

20. Ji H.B., Tang W., Zhou X.L., Wu Y., Combined effects of blue and ultraviolet lights on the accumulation of flavonoids in tartary buckwheat sprouts. Pol. J. Food. Nutr. Sci., 2016, 66, 93-98.

21. Kadlec P., Rubecova A., Hinkova A., Kaasova J., Bubnik Z., Pour $\mathrm{V}$., Processing of yellow pea by germination, microwave treatment and drying. Innov. Food. Sci. Emer., 2001, 2, 133-137.

22. Kwon Y., Lee K., Yun T., Choi S., Effect of heat pretreatment on the functional constituents of rice germ. Prev. Nutr. Food Sci., 2004, 9, 330-335.

23. Lee L.S., Choi E.J., Kim C.H., Sung J.M., Kim Y.B., Seo D.H., Choi H.W., Choi Y.S., Kum J.S., Park J.D., Contribution of flavonoids to the antioxidant properties of common and tartary buckwheat. J. Cereal Sci., 2016, 68, 181-186.

24. Li B.C., Li Y.Q., Hu Q.B., Antioxidant activity of flavonoids from tartary buckwheat bran. Toxicol. Environ. Chem., 2016, 98, SI, 429-438.

25. Li S.J., Bai Y.C., Li C.L., Yao H.P., Chen H., Zhao H.X., Wu Q., Anthocyanins accumulate in tartary buckwheat (Fagopyrum tataricum) sprout in response to cold stress. Acta. Physiol. Plant, 2015, 37, 1-8, art no. 159.

26. Li X.H., Park N.J., Park Ch.H., Kim S.G., Lee S.Y., Park S.U., Influence of sucrose on rutin content and flavonoid biosynthetic genes expression in seedlings of common buckwheat (Fagopyrum esculentum Moench). Plant Omics, 2011, 4, 215-219.

27. Łupinska A., Kozioł A., Araszkiewicz M., Łupinski M., The changes of quality in rapeseeds during microwave drying. Drying Technol., 2009, 27, 857-862.

28. Nam T.G., Lee S.M., Park J.H., Kim D.O., Baek N.I., Eom S.H., Flavonoid analysis of buckwheat sprouts. Food. Chem., 2015, 170, 97-101.

29. Onac I., Singureanu V., Moldovan G., Ungur R., High frequency pulsatile electromagnetic fields and ultrasound pulsatile fields impact on germination dynamic at Ocimum basilicum L. and O. basilicum var. purpurascens benth., observed with open source software. Not Bot. Horti. Agrob., 2016, 44, 41-47.

30. Orsak M., Lachman J., Vejdova M., Pivec V., Hamouz K., Changes of selected secondary metabolites in potatoes and buckwheat caused by UV, gamma- and microwave irradiation. Rost. Vyroba., 2001, 47, 493-500.

31. Pasko P., Barton H., Zagrodzki P., Gorinstein S., Folta M., Zachwieja Z., Anthocyanins, total polyphenols and antioxidant activity in amaranth and quinoa seeds and sprouts during their growth. Food. Chem., 2009, 115, 994-998.

32. Pelletier M.K., Burbulis I.E., Winkelshirley B., Disruption of specific flavonoid genes enhances the accumulation of flavonoid enzymes and end-products in arabidopsis seedlings. Plant Mol. Biol., 1999, 40, 45-54.

33. Radzevičius A., Sakalauskienė S., Dagys M., Simniškis R., Karklelienè R., Bobinas Č., Duchovskis P., The effect of strong microwave electric field radiation on: (1) vegetable seed germination and seedling growth rate. Zemdirbyste, 2013, 100, 179-184.

34. Ragha L., Mishra S., Ramachandran V., Bhatia M.S., Effects of low-power microwave fields on seed germination and growth rate. JEMAA, 2011, 3, 5, 165-171.

35. Rajjou L., Duval M., Gallardo K., Catusse J., Bally J., Job C., Job D., Seed germination and vigor. Annu. Rev. Plant Biol., 2012, 63, 507-533.

36. Randhir R., Shetty K., Microwave-induced stimulation of L-DOPA, phenolics and antioxidant activity in fava bean (Vicia faba) for Parkinson's diet. Process Biochem., 2004, 39, 1775-1784.

37. Roux D., Vian A., Girard S., Bonnet P., Paladian F., Davies E., Ledoigt G., Electromagnetic fields (900 MHz) evoke consistent molecular responses in tomato plants. Physiologia Plantarum, 2006, 128, 283-288.

38. Seo D.H., Kim M.S., Choi H.W., Sung J.M., Park J.D., Kum J.S., Effects of millimeter wave treatment on the germination rate and antioxidant potentials and gamma-aminobutyric acid of the germinated brown rice. Food. Sci. Biotechnol., 2016, 25, 111-114.

39. Seo J.M., Arasu M.V., Kim Y.B., Park S.U., Kim S.J., Phenylalanine and LED lights enhance phenolic compound production in tartary buckwheat sprouts. Food. Chem., 2015, 177, 204-213.

40. Stan M., Soran M.L., Varodi C., Lung I., Influence of microwave field on the ascorbic acid content in leaves of some common aromatic plants in Romania. Stud. U. Babes-Bol. Chem., 2014, 59, 125-133.

41. Thwe A.A., Kim Y., Li X., Kim Y.B., Park N.I., Kim H.H., Kim S.J., Park S.U., Accumulation of phenylpropanoids and corre- 
lated gene expression in hairy roots of tartary buckwheat under light and dark conditions. Appl. Biochem. Biotechnol., 2014, $174,2537-2547$.

42. Uppal V., Bains K., Effect of germination periods and hydrothermal treatments on in vitro protein and starch digestibility of germinated legumes. J. Food. Sci. Tech. Mysore, 2012, 49, 184-191.

43. Wang Z., Cao W., Dai T., Changes of endogenous plant hormones and soluble sugars and proteins during floret development and degeneration in wheat. Acta Agronomica Sinica, 2001, 27, 447-452 (in Chinese; English abstract).

44. Yu M., Liu H.Z., Shi A.M., Liu L., Wang Q., Preparation of resveratrol-enriched and poor allergic protein peanut sprout from ultrasound treated peanut seeds. Ultrason. Sonochem., 2016, 28, 334-340.
45. Zhang G., Xu Z., Gao Y., Huang X., Zou Y., Yang T., Effects of germination on the nutritional properties, phenolic profiles, and antioxidant activities of buckwheat. J. Food. Sci., 2015, 80, H1111-1119.

46. Zhou X.L., Hao T.F., Zhou Y.M., Tang W., Xiao Y., Meng X., Fang X., Relationships between antioxidant compounds and antioxidant activities of tartary buckwheat during germination. J. Food. Sci. Tech. Mysore, 2015a, 52, 2458-2463.

47. Zhou Y.M., Wang H., Cui L.L., Zhou X.L., Tang W., Song X.L., Evolution of nutrient ingredients in tartary buckwheat seeds during germination. Food. Chem., 2015b, 186, 244-248.

Submitted: 16 January 2017. Revised: 20 March, 8 April, 14 June, 23 June, and 25 July 2017. Accepted: 28 July 2017. Published online: 7 February 2018. 
